\title{
Preparation of Gradient Materials with Molten Salts Electrodeposition
}

\author{
Hui Li, Jinglong Liang *, Hongyan Yan, Yungang Li and Le Wang
}

\begin{abstract}
College of Metallurgy and Energy, North China University of Science and Technology, Tangshan 063210, China; lh@ncst.edu.cn (H.L.); yanhy@ncst.edu.cn (H.Y.); lyg@ncst.edu.cn (Y.L.); wangl@ncst.edu.cn (L.W.)

* Correspondence: lil@ncst.edu.cn
\end{abstract}

Citation: Li, H.; Liang, J.; Yan, H.; Li, Y.; Wang, L. Preparation of Gradient Materials with Molten Salts Electrodeposition. Crystals 2021, 11, 590. https://doi.org/10.3390/ cryst 11060590

Academic Editor: Pavel Lukáč

Received: 15 April 2021

Accepted: 19 May 2021

Published: 24 May 2021

Publisher's Note: MDPI stays neutral with regard to jurisdictional claims in published maps and institutional affiliations.

Copyright: (c) 2021 by the authors. Licensee MDPI, Basel, Switzerland This article is an open access article distributed under the terms and conditions of the Creative Commons Attribution (CC BY) license (https:// creativecommons.org/licenses/by/ $4.0 /)$.
Abstract: A new way of preparing W-Cu functional gradient materials (FGM) with molten salts electrodeposition is studied. The results show that, with the conditions of current density $70 \mathrm{~mA} \cdot \mathrm{cm}^{-2}$, electrodeposition temperature $700{ }^{\circ} \mathrm{C}$ and bidirectional pulse electrodepositing for 30 minutes (min), the $\mathrm{Cu}-\mathrm{Ni}$ gradient layer prepared under this condition is widely used dense and smooth. Fundamental to the preparation of $\mathrm{Cu}-\mathrm{Ni}$ functional gradient layer, $\mathrm{Cu}-\mathrm{Ni}$ is used as a cathode to deposit $\mathrm{W}$. Under the current density of $50 \mathrm{~mA} \cdot \mathrm{cm}^{-2}$, the time of $20 \mathrm{~min}$, with bidirectional pulse electrodeposition, the $\mathrm{Cu}+\mathrm{Ni}+\mathrm{W}$ gradient layer has uniform composition gradient change and larger thickness. The $\mathrm{W}-\mathrm{Cu}$ gradient materials prepared in this study have good cohesiveness. The addition of $\mathrm{Ni}$ would promote the inter-diffusion of $\mathrm{Cu}$ and $\mathrm{W}$, and increase the diffusion coefficient significantly.

Keywords: $\mathrm{Cu}-\mathrm{W}$ gradient material; molten salts electrodeposition; $\mathrm{Cu}-\mathrm{Ni}-\mathrm{W}$

\section{Introduction}

As it can alleviate the thermal stress caused by the mismatch of the thermal properties of tungsten and copper, W-Cu FGM can obtain better comprehensive properties, such as better mechanical properties, corrosion resistance, and thermal shock resistance. These properties enable W-Cu FGM to be better used in many special environments, such as aerospace, nuclear industry, and other high-tech fields. Since tungsten and copper neither chemically react nor dissolve each other, and both have low wettability, the preparation of $\mathrm{W} / \mathrm{Cu}$ composite materials is difficult. Some researchers have successfully prepared ablative and thermal-shock-resistant W-Cu Functional Graded Material [1]. The research of W-Cu Functional Gradient Materials (FGM) will become the focus of research on functionally graded materials by plasma spraying [2-5]. There are many methods to prepare the $\mathrm{W}-\mathrm{Cu}$ composite materials with molten salt electrodeposition. With $\mathrm{WF}_{6}$ as the raw materials, Senderoff [6] studied the theory and process of molten salts electrodeposition of tungsten and obtained a dense tungsten gradient layer with good adhesion. Based on the $\mathrm{ZnCl}_{2}-\mathrm{NaCl}$ (60:40) and $\mathrm{ZnBr}_{2}-\mathrm{NaBr}$ (60:40) system, Katagiri A obtained a tungsten deposition layer with a smooth surface, high density, good adhesion, and a slightly metallic luster. To improve the quality of the gradient layer, the reverse cycle electrodeposition technique has been adopted [7]. Pavlovskii VA [8,9] obtained a thickness of $15 \sim 60 \mu \mathrm{m}$ tungsten coating through $\mathrm{NaF}$ : $\mathrm{NaCl}: \mathrm{WO}_{3}=3$ : 12: 5 (mass ratio) molten salt system. $\mathrm{K}$ Koyama [10] obtained a thickness of $100 \mu \mathrm{m}$ tungsten deposition coating from $\mathrm{KF}-\mathrm{B}_{2} \mathrm{O}_{3}-$ $\mathrm{WO}_{3}$ molten salt system. $\mathrm{K}$ Nitta [11] obtained a thickness of $13 \mu \mathrm{m}$ tungsten coating of $\mathrm{W}-$ $\mathrm{Cu}-\mathrm{W}$ material based on a molten salt system of molar ratio of $\mathrm{KF}: \mathrm{B}_{2} \mathrm{O}_{3}: \mathrm{WO}_{3}=67: 26: 7$.

The physical properties of tungsten and copper are significantly different [12-17]. Cracks occur on the $\mathrm{W}$-side or the combination surface of $\mathrm{W}$ and $\mathrm{Cu}$, making the materials useless [18,19]. There are still some deficiencies in the electrode-position process and the electrolyte system of the tungsten deposition, which is needed to be further studied and improved [20]. 
Because $\mathrm{Cu}$ and $\mathrm{Ni}$ can be completely soluble in each other, $\mathrm{Ni}$ and $\mathrm{W}$ alloys can be obtained by electrodeposition. The method of molten salt electrodeposition was applied to prepare W-Cu FGM, where nickel was used as a bridge of connection between tungsten and copper. Firstly, $\mathrm{Cu}-\mathrm{Ni}$ gradient materials in the $\mathrm{NaCl}-\mathrm{KCl}-\mathrm{NaF}-\mathrm{NiO}$ molten salt system was prepared. Then, $\mathrm{Cu}-\mathrm{Ni}$ gradient materials, as a cathode to electrodeposit $\mathrm{W}$, were made in the $\mathrm{NaCl}-\mathrm{KCl}-\mathrm{NaF}-\mathrm{WO}_{3}$ molten salt system. Finally, the W-Cu FGM was prepared with changes from $\mathrm{Cu}$ to $(\mathrm{Cu}+\mathrm{Ni}+\mathrm{W})$ to $\mathrm{W}$.

\section{Materials and Methods}

The reagents used in the experiment were all analytically pure. The reagents were dried at $200{ }^{\circ} \mathrm{C}$ for $8 \mathrm{~h}$ to completely remove the adsorbed water and then put in a dry dish for use after cooling and grinding. The electrolytic cell used in this study was a corundum crucible as a molten pool, and a stainless steel electrode was used as a cathode and graphite as an anode. At the same time, the $\mathrm{NaCl}-\mathrm{KCl}-\mathrm{NaF}$ molten salt system was used, argon was used as the protective gas, and the electrolyte mass volume was $200 \mathrm{~g}$. Electrode sheet uses stainless steel rod was used as suspension carrier. Electrode sheet with a stainless steel rod as suspension carrier was used. The size of cathode used in the experiment was $20 \mathrm{~mm} \times 20 \mathrm{~mm} \times 1 \mathrm{~mm}$. The samples were polished with an 800\# abrasive paper to remove the rust on the substrate surface and then were polished with $1 \sim 3 \#$ metallographic abrasive paper. The samples were soaked in $\mathrm{NaOH}$ aqueous solutions for $10 \mathrm{~min}$ and then were cleaned thoroughly and dry.

\subsection{The Preparation of $\mathrm{Cu}-\mathrm{Ni}$ Gradient Materials}

The experimental results showed that the reagents mixed with the molar ratio of $\mathrm{NaCl}$ : $\mathrm{KCl}: \mathrm{NaF}: \mathrm{NiO}=0.36: 0.36: 0.25: 0.02$ could achieve a better deposited coating, and they were put into a graphite crucible for the experiment [21]. The experiment was performed in a resistance furnace, ventilating with argon gas. The samples were heated and kept at constant preset temperature for $9 \mathrm{~h}$ to dissolve $\mathrm{NiO}$. Then, the prefabricated nickel anode sheet $(20 \mathrm{~mm} \times 50 \mathrm{~mm} \times 3 \mathrm{~mm})$ and copper cathode sheet $(20 \mathrm{~mm} \times 20 \mathrm{~mm} \times 1 \mathrm{~mm})$ were put into the crucible, and a bidirectional pulse was energized (pulse cycle: $\mathrm{T}=1000 \mathrm{~ms}$; the forward and reverse current ratio: $\mathrm{i}_{\mathrm{f}} / \mathrm{i}_{\mathrm{r}}=6: 1$; the forward and reverse time ratio: $t_{\mathrm{f}} / t_{\mathrm{r}}=3: 1$ ). The following parameters were also used: the current density, $70 \mathrm{~mA} \cdot \mathrm{cm}^{-2}$; electrodeposition temperature, $700{ }^{\circ} \mathrm{C}$; electrodeposition time, $10-50 \mathrm{~min}$. After the electrodeposition, the cathode copper was lifted rapidly, and the samples were regenerated into the boiled distilled water to remove the molten salt on the sheet.

\subsection{The Ni-W Gradient Layer Material Preparation}

To get the better deposited coating, the reagents were mixed with the molar ratio of $\mathrm{NaCl}: \mathrm{KCl}: \mathrm{NaF}: \mathrm{WO}_{3}=0.3385: 0.3385: 0.25: 0.073$ and then were put into graphite crucible for the experiment [21]. The experiment was also performed in the resistance furnace ventilating with argon gas. The samples were heated and kept at $700{ }^{\circ} \mathrm{C}$ for 6 hours to dissolve $\mathrm{WO}_{3}$. For electrodeposition, a nickel sheet $(20 \mathrm{~mm} \times 20 \mathrm{~mm} \times 1 \mathrm{~mm})$ was used as a cathode and a tungsten sheet $(20 \mathrm{~mm} \times 50 \mathrm{~mm} \times 3 \mathrm{~mm})$ as an anode. Pulse period $\mathrm{T}=1000 \mathrm{~ms}$; the forward and reverse current ratio: $\mathrm{i}_{\mathrm{f}} / \mathrm{i}_{\mathrm{r}}=6: 1$; the forward and reverse time ratio: $t_{\mathrm{f}} / t_{\mathrm{r}}=3: 1$, molten salt temperature $700{ }^{\circ} \mathrm{C}$, current density $50 \mathrm{~mA} \cdot \mathrm{cm}^{-2}$, and electrodeposition time $=10 \mathrm{~min}$.

\subsection{Preparation of $\mathrm{Cu}-\mathrm{Ni}-\mathrm{W}$ Gradient Layer Materials}

The $\mathrm{Cu}-\mathrm{Ni}$ gradient material obtained in the experiment was used as cathode in the molten salt system and a pure tungsten sheet $(20 \mathrm{~mm} \times 50 \mathrm{~mm} \times 3 \mathrm{~mm})$ as anode. The electrodeposition conditions of the experiment were adopted as 1.2, and the deposition time was $20 \mathrm{~min}$. After the electrodeposition was over, the cathode copper plate was quickly lifted out, put into pre-boiled distilled water to remove the molten salt attached to the cathode substrate, rinsed, and dried for later use. The resistance furnace was used 
for heating, which was controlled by AI (artificial intelligence) regulator (AI-808p), the temperature measuring thermocouple was a platinum-platinum-rhodium thermocouple, and the electrodeposition power supply was an intelligent multi-group commutation pulse electroplating power supply (Handan Daysun Electroplating Equipment Co., Ltd., Handan, China). Quanta 650 field emission scanning electron microscope (FEI company, Waltham, USA) was used to analyze the microscopic surface morphology and cross-sectional morphology of the sample and the energy spectrum components. GDA750 glow discharge instrument was used to analyze the variation of $\mathrm{Cu}$ and $\mathrm{Ni}$ content with depth in the cross-section of the sample.

\section{Results}

\subsection{Analysis of $\mathrm{Cu}-\mathrm{Ni}$ Gradient Layer Formation Mechanism}

As shown in Figure 1, the content of Ni on the surface of the gradient layer was $27.73 \%$. The surface content of the sample was plated with Ni compared with the surface of pure copper. Figure 2 shows the SEM image of the sample section morphology. As indicated in Figure 2, the $\mathrm{Cu}-\mathrm{Ni}$ gradient layer is was uniform and had a thickness of about $6 \mu \mathrm{m}$. In addition, there was better metallurgical bonding between the plating layer and the substrate. This is because $\mathrm{Cu}$ and $\mathrm{Ni}$ can form a solid solution, and a gradient layer with a certain thickness can be formed at the interface. This is because, during the process of $\mathrm{Ni}$ electrodeposition, the nickel ions in the molten salt migrated to the surface of the cathode copper sheet under the action of an electric field, were reduced to nickel by the electrons, and adhered to the surface of the copper sheet. The nickel then proceeded from the surface to the inside of the copper sheet. Finally, a diffusion layer with a certain nickel content is formed. The process of this diffusion layer is as follows: the nickel ions diffuse from the molten salt to the interface of the copper sheet, then diffuse between the electrical double layers of the interface of electrons participating in the reaction, and then diffuse to the interface into the solid interior.

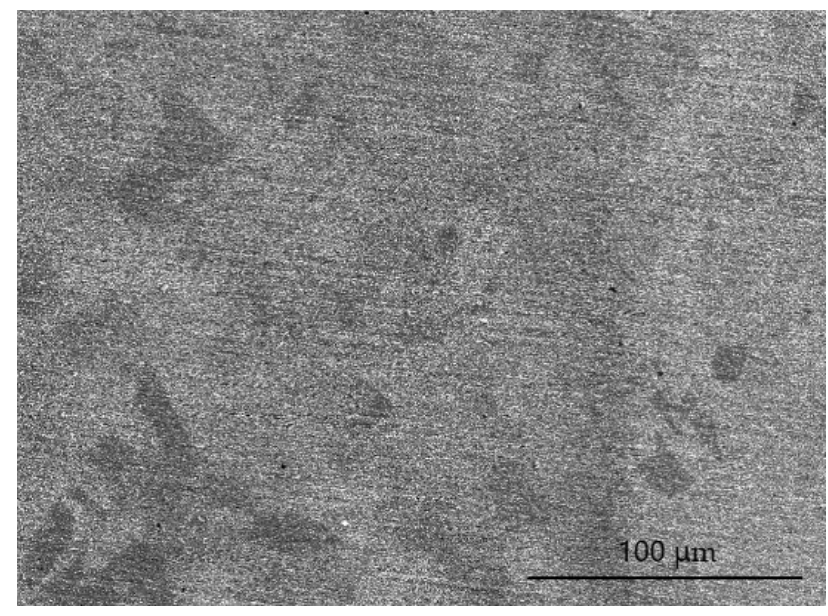

(a)

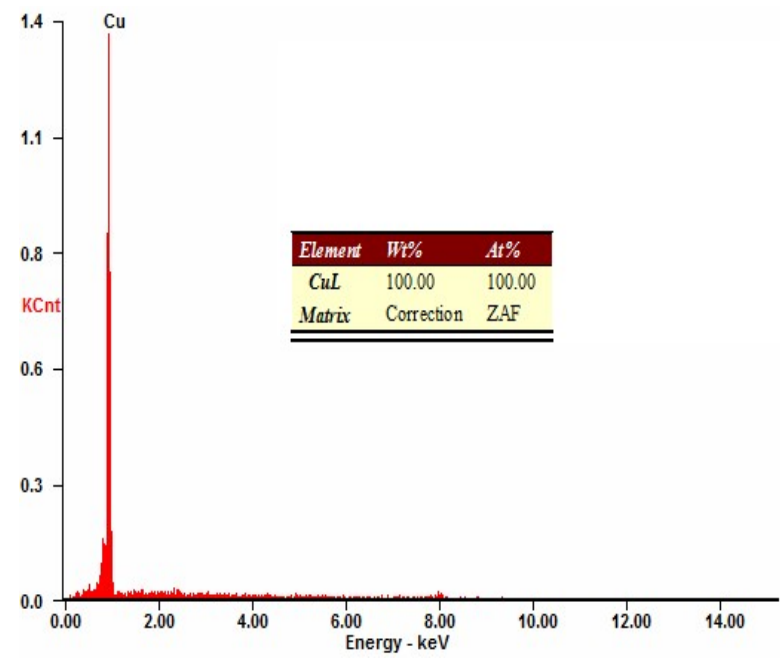

(b)

Figure 1. Cont. 


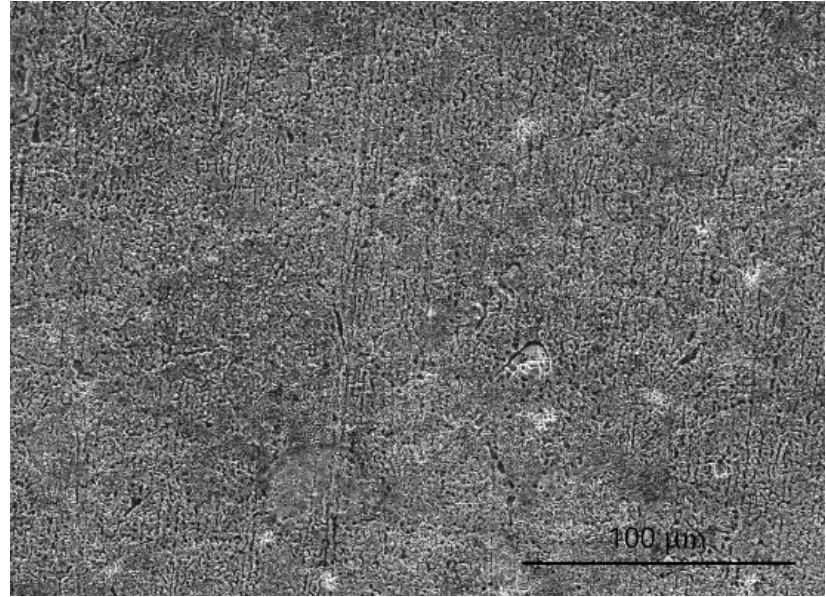

(c)

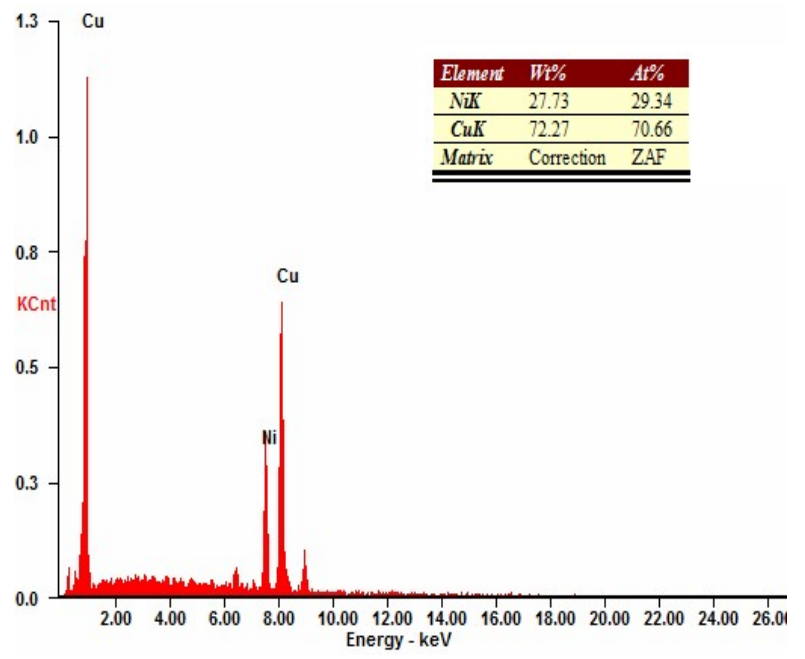

(d)

Figure 1. Images (left) and spectra (right) of sample surface morphology: (a) image of $\mathrm{Cu},(\mathbf{b})$ spectra of $\mathrm{Cu}$, (c) image of $\mathrm{Cu}-\mathrm{Ni}$, (d) spectra of $\mathrm{Cu}-\mathrm{Ni}$.

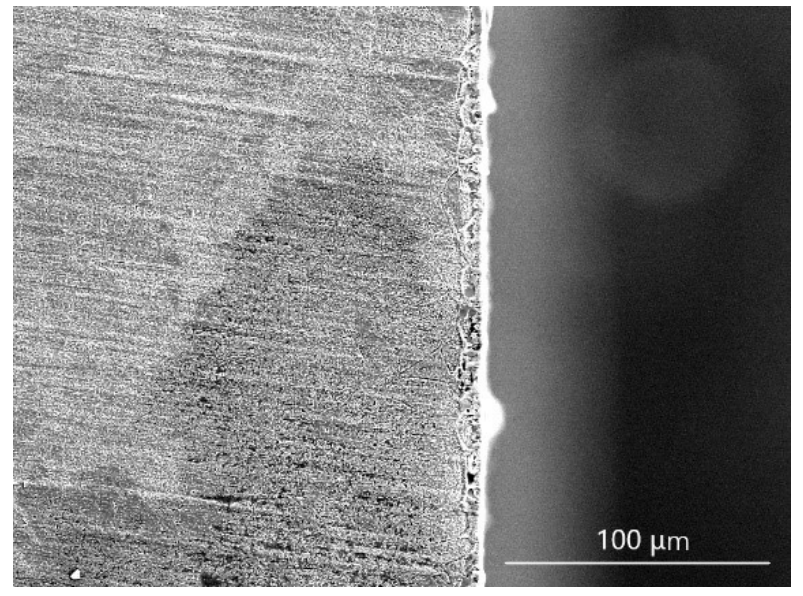

(a)

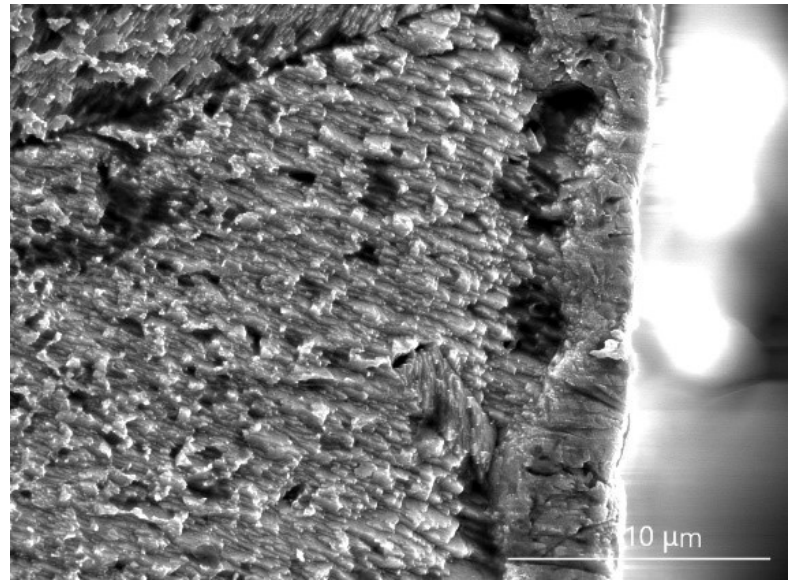

(b)

Figure 2. SEM image of sample section morphology (a) low magnification (b) high magnification.

Figure 3 shows the content distribution of $\mathrm{Cu}, \mathrm{Ni}$. When the time was at $10 \mathrm{~min}$, the thickness is less than $2 \mu \mathrm{m}$. When the time is at $50 \mathrm{~min}$, the thickness was close to $9 \mu \mathrm{m}$. As the time increased, the $\mathrm{Ni}$ content on the deposition layer presented a growth trend. However, from $30 \mathrm{~min}$ to $50 \mathrm{~min}$, the Ni content stayed still. The reason for this phenomenon is that $\mathrm{Ni}$ continuously gains electrons to be deposited on the surface of the copper sheet as time goes on in the electrodeposition process. Since the two elements $\mathrm{Cu}$ and $\mathrm{Ni}$ are completely miscible, the deposited $\mathrm{Ni}$ and $\mathrm{Cu}$ are solid-state interdiffusion. On the side close to the $\mathrm{Cu}$ substrate, the Ni content gradually decreased and had a gradient distribution. The nickel ions on the surface of the copper sheet were gradually consumed as the deposition progresses. The nickel ions in the molten salt needed to be supplemented by diffusion and mass transfer to the cathode copper surface. When the diffusion and mass transfer speed in the molten salt was lower than the electron speed obtained by electrodeposition, the deposition rate was affected due to the diffusion control rate. At the same time, when the inter-diffusion rate of $\mathrm{Ni}$ and $\mathrm{Cu}$ was much greater than the electrodeposition rate of $\mathrm{Ni}, \mathrm{Ni}$ continued to diffuse into the $\mathrm{Cu}$ substrate, so no pure $\mathrm{Ni}$ layer was formed on the surface of the $\mathrm{Cu}$ substrate. Solid-state diffusion relies on thermal activation of the atom. Increasing the diffusion rate could not increase the thickness of 
the graded layer. The probability of atom migration increases with the increase in the transition temperature, and the distance of atom migration increases with the increase in the transition time.

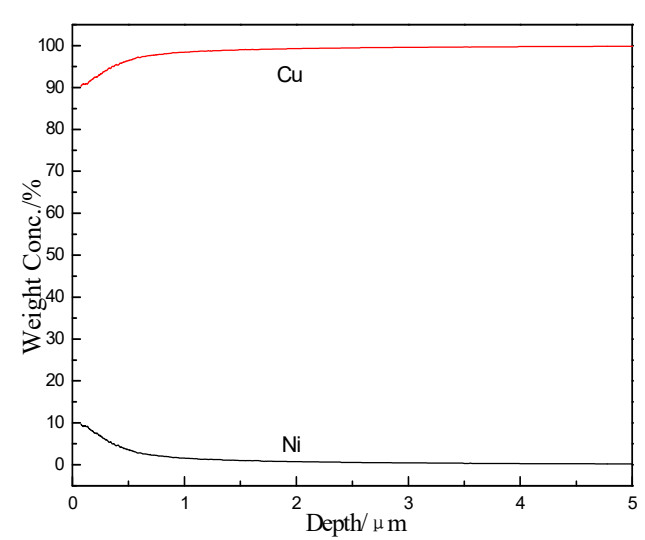

(a)

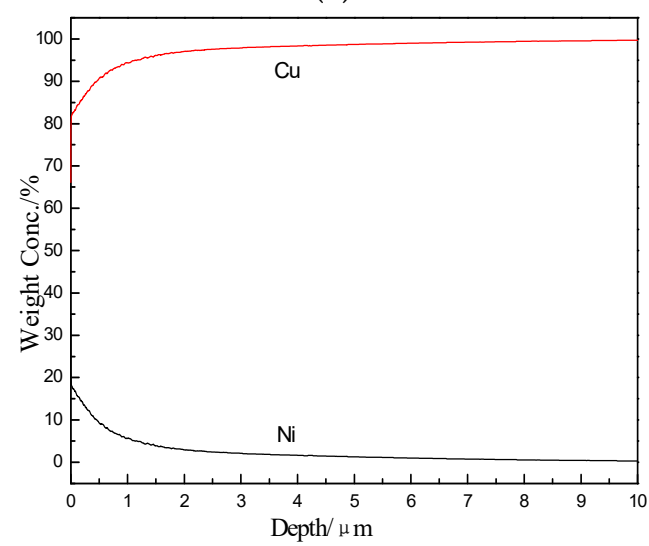

(c)

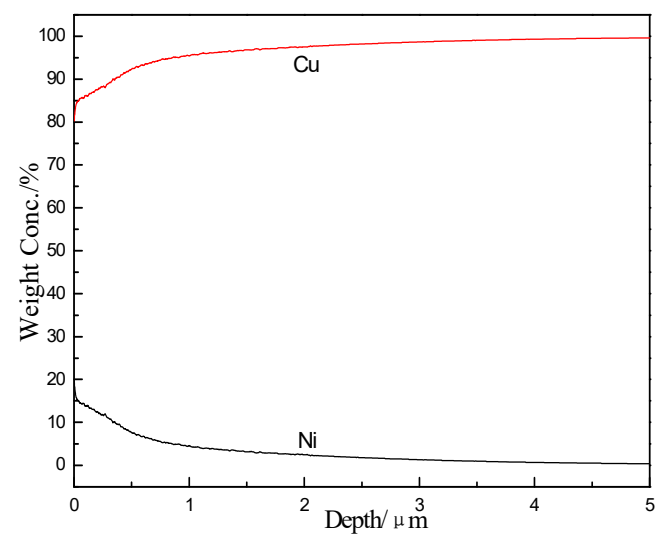

(b)

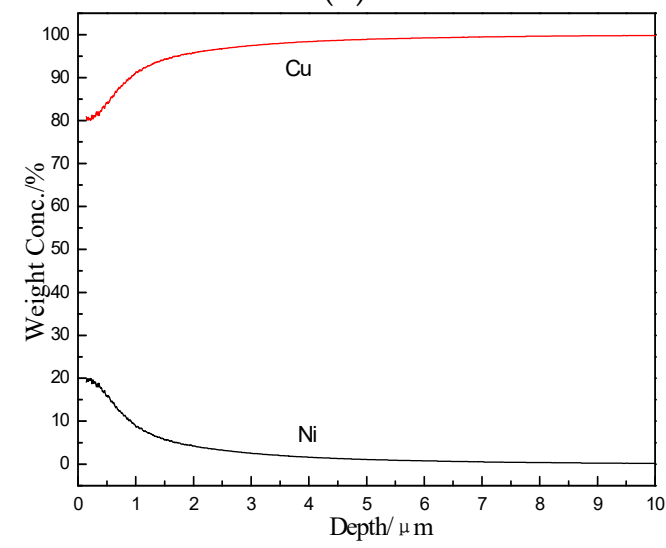

(d)

Figure 3. The content distributing of $\mathrm{Cu}$, Ni at different times: (a) $10 \mathrm{~min}$ (b) $20 \mathrm{~min}$ (c) $30 \mathrm{~min}$ (d) $50 \mathrm{~min}$.

$\mathrm{Cu}$ and $\mathrm{Ni}$ contact each other to form a $\mathrm{Cu} / \mathrm{Ni}$ interface, and diffusion occurs at the phase interface during heating. The diffusion behavior of $\mathrm{Cu}$ and $\mathrm{Ni}$ atoms is different under the same temperature. As the melting point and binding energy of $\mathrm{Cu}$ are lower than those of $\mathrm{Ni}$, the temperature during electrodeposition at $700{ }^{\circ} \mathrm{C}$ reached 0.65 times the melting point of $\mathrm{Cu}$, so $\mathrm{Cu}$ atoms were first thermally activated and began to diffuse; while $700{ }^{\circ} \mathrm{C}$ only has the melting point 0.48 times higher than that of $\mathrm{Ni}$, most of the $\mathrm{Ni}$ atoms cannot be thermally activated and diffused, and only a very small number of $\mathrm{Ni}$ atoms at the lattice distortion defect are thermally activated and diffused. Since the $\mathrm{Cu}-\mathrm{Ni}$ alloy is a replacement solid solution, the diffusion mechanism is a vacancy diffusion mechanism [22]. At this time, a large number of $\mathrm{Cu}$ atoms cross the $\mathrm{Cu} / \mathrm{Ni}$ interface and migrate to the side of $\mathrm{Ni}$ through the vacancy diffusion mechanism, while only a very small number of $\mathrm{Ni}$ atoms diffuse and migrate to the side of the $\mathrm{Cu}$.

\subsection{The Feature of Ni-W Gradient Layer}

The experimental results of depositing $\mathrm{W}$ on $\mathrm{Ni}$ cathode were analyzed to determine the feasibility of $\mathrm{Ni}$ as a connecting metal.

\subsubsection{The Analysis of the Constituents}

Figure 4 shows the SEM images and EDS spectra of sample surface morphology and section morphology. As indicated in Figure 4, the surface of Ni-W gradient layers is pure $\mathrm{W}$, while both $\mathrm{Ni}$ and $\mathrm{W}$ are distributed on the cross-section. 


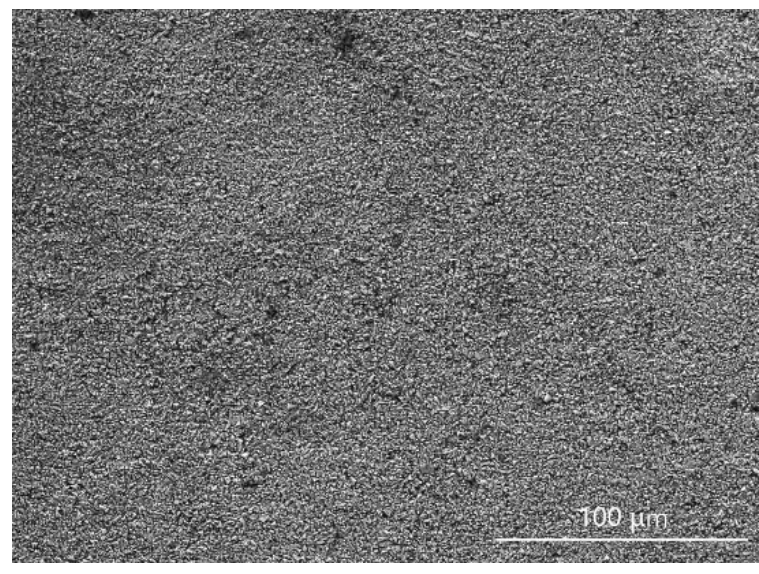

(a)

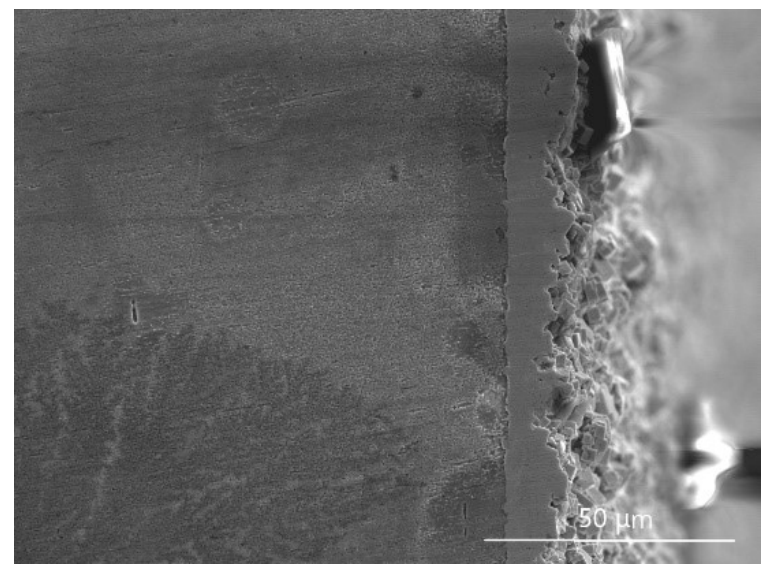

(c)

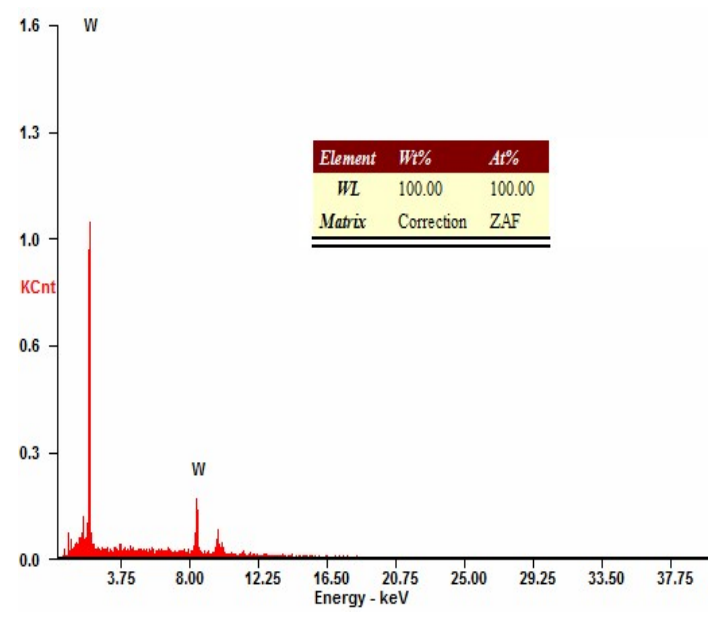

(b)

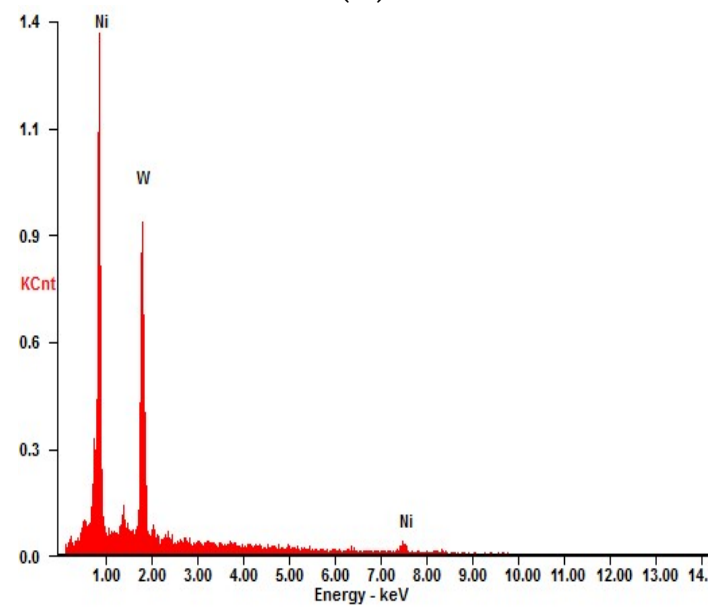

(d)

Figure 4. SEM images (left) and EDS spectra (right) of sample: (a) surface SEM images, (b) surface EDS spectra, (c) section SEM images, (d) section EDS spectra.

\subsubsection{The Analysis of Sample Cross-section}

Figure 5 shows an electron microscope photo of the sample cross-section at low and high magnification. It can be seen that the thickness of the coating is uniform at about $10 \mu \mathrm{m}$, and the coating is tightly bonded to the substrate. Figure 6 shows the backscattered electron image of sample section morphology. As the principle of Back-Scattered Electron Imaging (BSE) indicates, the coefficient of material of atoms is smaller if the image is darker, whereas the atomic coefficient is larger with a brighter image. Combining this information with that of Figure 5, because there are Ni and $\mathrm{W}$ on the cross-section and different backscattered contrast atoms shows different lightness, the section morphology can be divided into two colors: gray and white. Since the atomic coefficient of $\mathrm{W}$ is larger than that of $\mathrm{Ni}$, the white morphology is W, and the gray is Ni. It can also be seen from the figure that the substrate is mainly $\mathrm{Ni}$, and the plating layer obtained by electrodeposition is mainly $\mathrm{W}$. The deposition layer is not only uniform but also well combined with the substrate.

From the above analysis, it can be inferred that the $\mathrm{Ni}-\mathrm{W}$ gradient layer can be obtained in the $\mathrm{NaCl}-\mathrm{KCl}-\mathrm{NaF}-\mathrm{WO} 3$ molten salt system. Ni is feasible as a connecting metal of $\mathrm{Cu}$ and $\mathrm{W}$. 


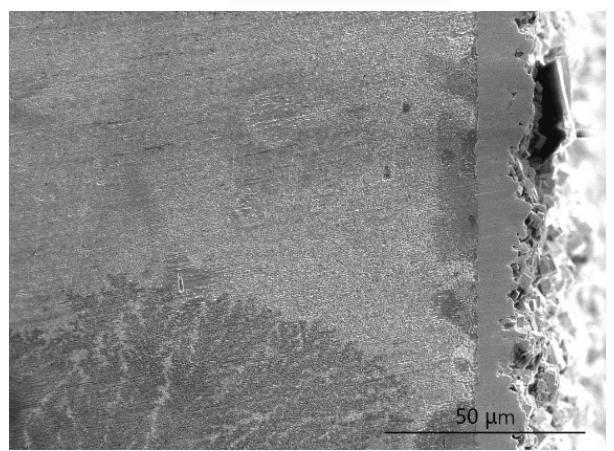

(a)

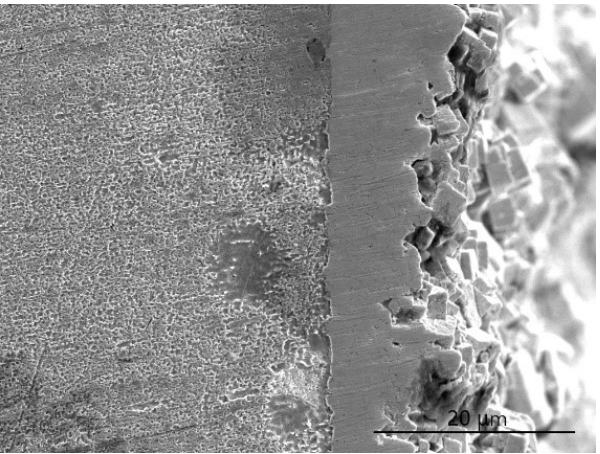

(b)

Figure 5. SEM image of sample section morphology: (a) low magnification (b) high magnification.

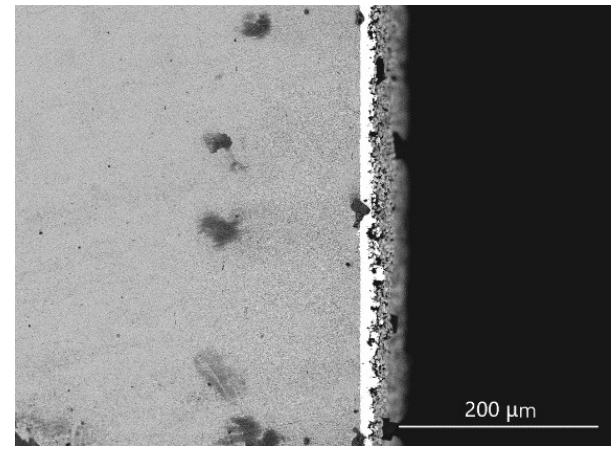

(a)

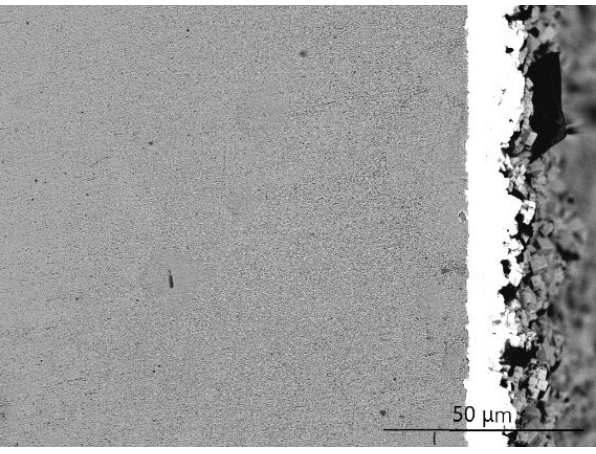

(b)

Figure 6. The backscattered electron image of sample section morphology: (a) low magnification (b) high magnification.

\subsection{The Characteristics of $\mathrm{Cu}-\mathrm{Ni}-\mathrm{W}$ Gradient Layer}

As shown in Figure 7a, the cohesion between the electrodeposition layer and the substrate is close and complete, and there are no cracks and holes. There is also a relatively close cohesion between the electrodeposited layers. Figure $7 \mathrm{~b}$ shows a backscattered electron image of sample section morphology. Because the atomic coefficient of $W$ is larger than that of $\mathrm{Cu}$ and $\mathrm{Ni}$, the white morphology is W. Figure 8 is the EDS surface scanning of the element distribution of $\mathrm{Cu}, \mathrm{Ni}$, and $\mathrm{W}$ of the sample cross-section. The elements contained in the cross-section of the sample are $\mathrm{Cu}, \mathrm{Ni}, \mathrm{W}$, and the order of the distribution from the substrate to the outer surface is $\mathrm{Cu} \rightarrow \mathrm{Cu}+\mathrm{Ni}+\mathrm{W} \rightarrow \mathrm{W}$, where $\mathrm{Cu}, \mathrm{Ni}$, and $\mathrm{W}$ present a gradient distribution.

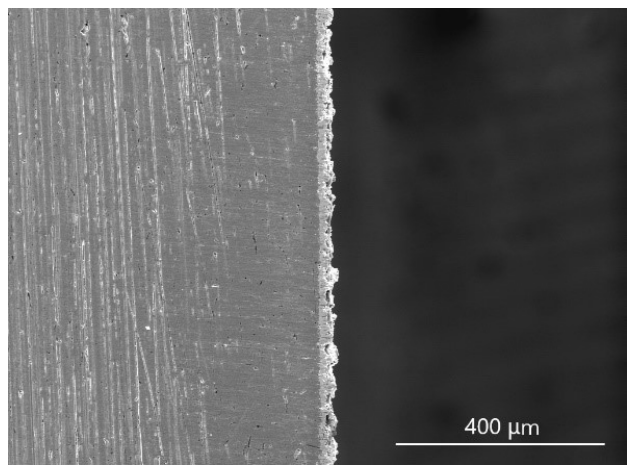

(a)

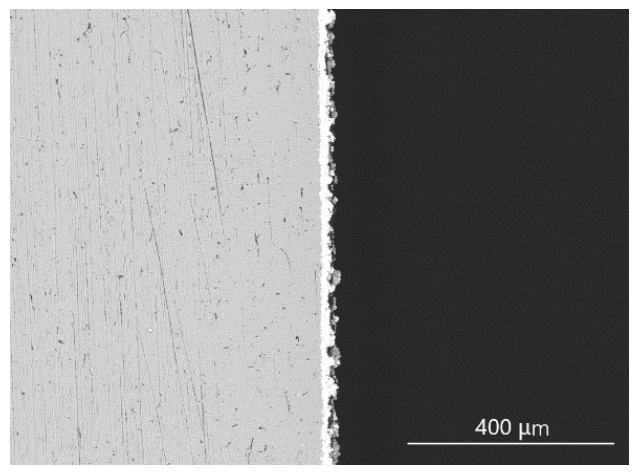

(b)

Figure 7. SEM image and backscattered electron image of sample section morphology: (a) SEM (b) backscattered electron image. 


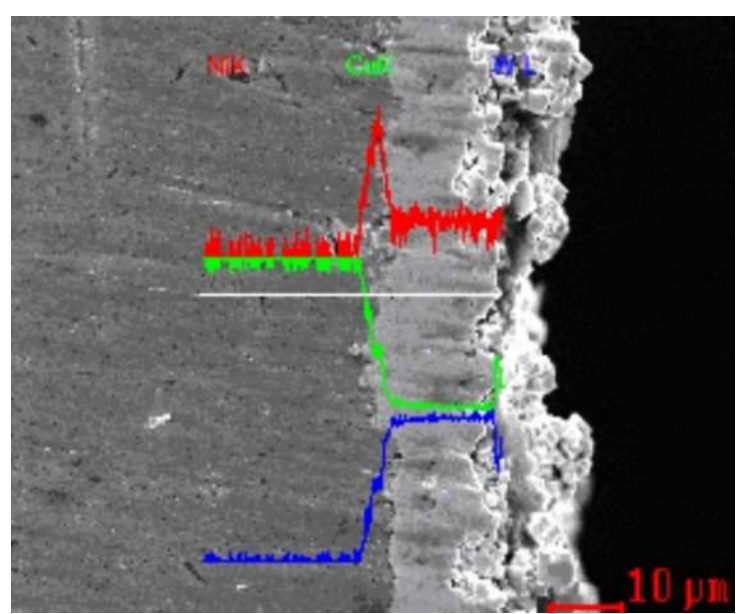

(a)

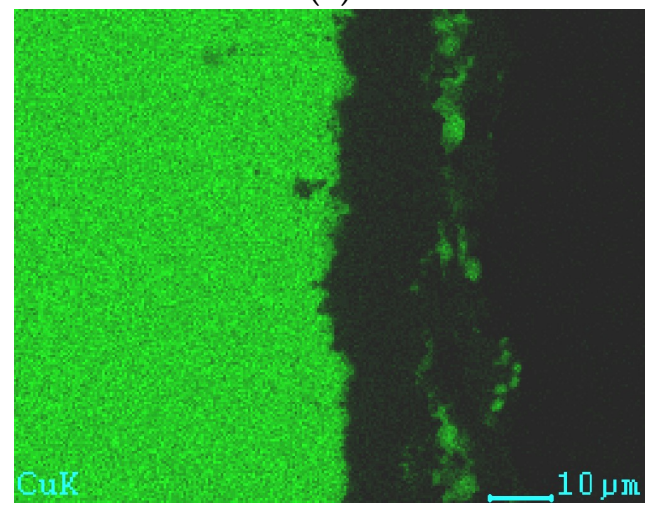

(c)

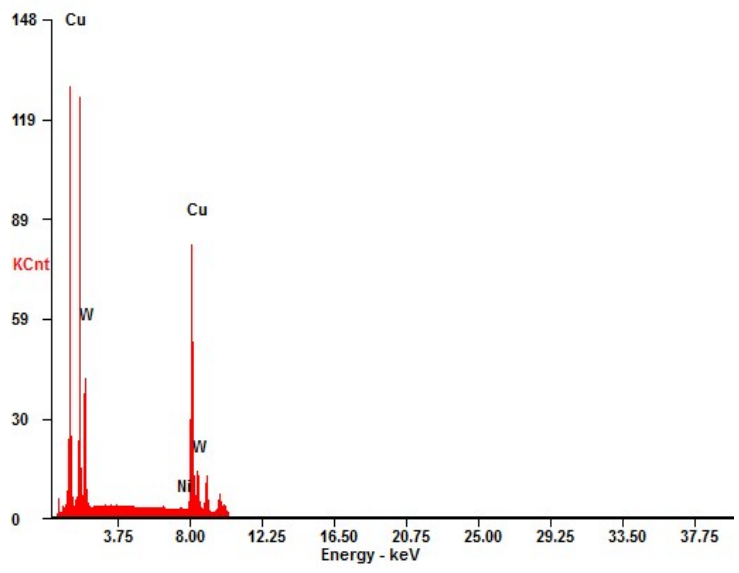

(b)

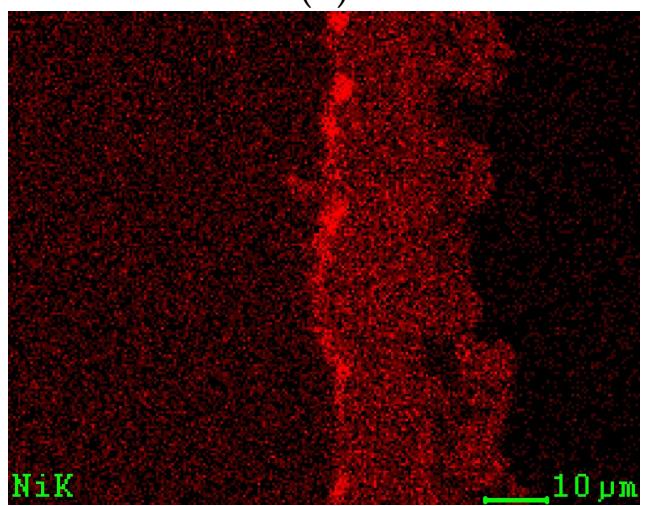

(d)

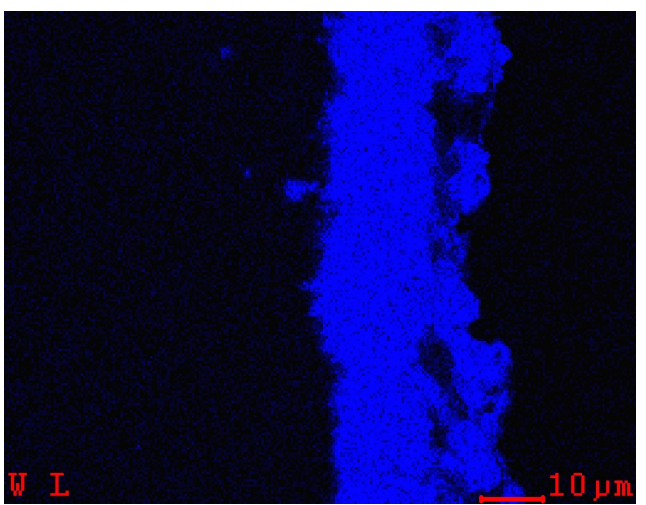

(e)

Figure 8. The $\mathrm{Cu}, \mathrm{Ni}$, and $\mathrm{W}$ element distribution map of sample section EDS surface scanning: (a) SEM, (b) EDS, (c) Cu, (d) $\mathrm{Ni},(\mathbf{e}) \mathrm{W}$.

\subsection{The Role of Ni to $\mathrm{Cu}-\mathrm{W}$ Gradient Layer's Formation}

As the bridge between $\mathrm{W}$ and $\mathrm{Cu}$, it is easy for $\mathrm{Ni}$ to form a solid solution with $\mathrm{Cu}$, and it is easy to form a solid solution of inter-metallic compound with $\mathrm{W}$, which makes $\mathrm{W}$ and $\mathrm{Cu}$ achieve good properties. This solves the miscibility problem of $\mathrm{W}$ and $\mathrm{Cu}$ and increases the thickness of the $\mathrm{Cu}-\mathrm{W}$ gradient layer. Figure 9 shows the content distribution of $\mathrm{Cu}$ and $\mathrm{W}$ : (a) $\mathrm{Cu}-\mathrm{W}$, and (b) $\mathrm{Cu}-\mathrm{Ni}-\mathrm{W}$. On electrodepositing $\mathrm{W}$, the preparation condition of $\mathrm{Cu}-$ $\mathrm{Ni}-\mathrm{W}$ is the same as that of $\mathrm{Cu}-\mathrm{W}$ : directional pulse, temperature $700^{\circ} \mathrm{C}$, current density $50 \mathrm{~mA} \cdot \mathrm{cm}^{-2}$, and electrodeposition time $10 \mathrm{~min}$. Figure 9 indicates that the thickness of $\mathrm{Cu}-\mathrm{W}$ gradient layer is $0.5 \mu \mathrm{m}$, which can be ignored. The thickness of $\mathrm{Cu}-\mathrm{Ni}-\mathrm{W}$ gradient layer is $12 \mu \mathrm{m}$. 


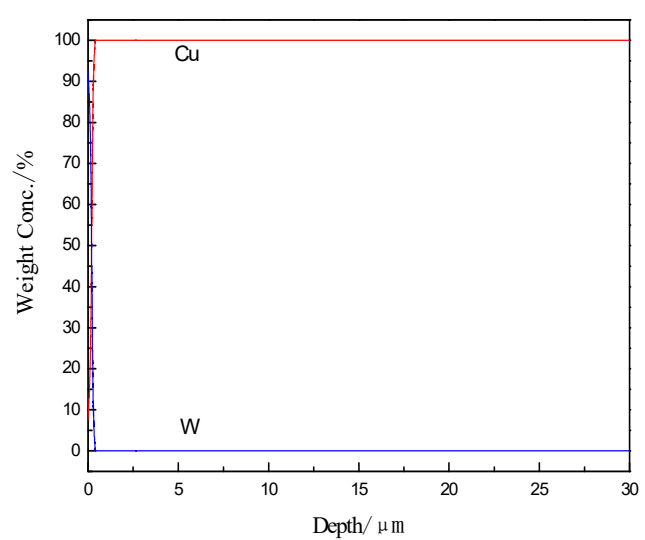

(a)

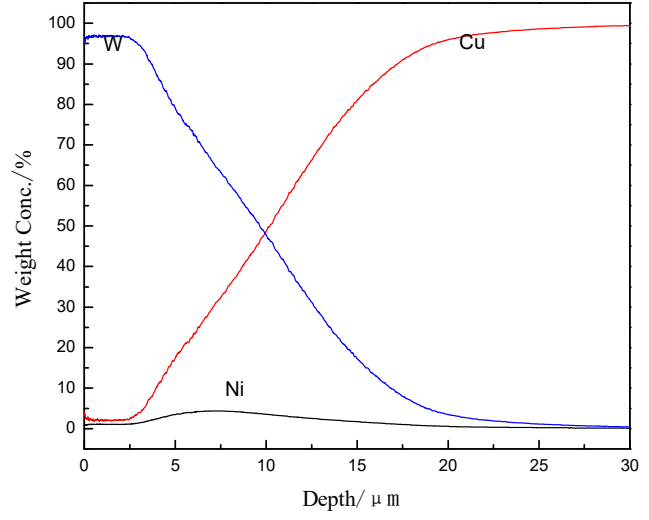

(b)

Figure 9. The content distributing of $\mathrm{Cu}$ and $\mathrm{W}$ : (a) $\mathrm{Cu}-\mathrm{W}$ and (b) $\mathrm{Cu}-\mathrm{Ni}-\mathrm{W}$.

At the condition of current density of $50 \mathrm{~mA} \cdot \mathrm{cm}^{-2}$, electrodeposition time $10 \mathrm{~min}$, the thickness of $\mathrm{Cu}-\mathrm{Ni}-\mathrm{W}$ gradient layer prepared at the temperature of $700-800{ }^{\circ} \mathrm{C}$ is shown in Table 1. Because there is little Ni in the layer, the study only considers the inter-diffusion between $\mathrm{Cu}$ and $\mathrm{W}$.

Table 1. Relationship of the temperature and gradient layer thickness.

\begin{tabular}{ccccc}
\hline Deposition Temperature $\mathbf{T} / \mathbf{K}$ & 973 & 1003 & 1033 & 1063 \\
\hline Thickness of $\mathbf{C u}-\mathbf{N i}-\mathbf{W}$ layer $\delta / \mu \mathrm{m}$ & 12 & 15 & 18 & 21 \\
\hline
\end{tabular}

Diffusion coefficient and temperature can be expressed as the Arrhenius equation:

$$
D=D_{0} \exp (-Q / R T)
$$

where $D_{0}$ is diffusion coefficient $\left(\mathrm{m}^{2} \cdot \mathrm{s}^{-1}\right), Q$ is diffusion activation energy $\left(\mathrm{J} \cdot \mathrm{mol}^{-1}\right), R$ is gas constant $\left(\mathrm{J} \cdot \mathrm{mol}^{-1} \cdot \mathrm{K}^{-1}\right)$, and $T$ is the absolute temperature $(\mathrm{K})$. With the Arrhenius equation and the relationship of permeability thickness and diffusion coefficient, the following equation can be derived [23]:

$$
\delta^{2}=D_{0} \cdot t \cdot \exp (-Q / R T)
$$

where $\delta$ is the average permeability thickness $(\mathrm{m}), t$ is the holding time (s). By taking the logarithm in both sides of the equation, the following equation can be derived:

$$
2 \ln \delta=-\frac{Q}{R T}+\ln D_{0} t
$$

According to the data in Table 1, a scatter diagram was made, which is shown in Figure 10. Fitting a straight line, we get $D_{0}=1.34 \times 10^{-7} \mathrm{~m}^{2} \cdot \mathrm{s}^{-1}, Q=106,880.51 \mathrm{~J} \cdot \mathrm{mol}^{-1}$. Substituting $D_{0}$ and $Q$ into formula (1), the mutual diffusion coefficient at $700{ }^{\circ} \mathrm{C}$ is calculated as $D=2.45 \times 10^{-13} \mathrm{~m}^{2} \cdot \mathrm{s}^{-1}$. It can be seen that due to the addition of the $\mathrm{Ni}$ element, the inter-diffusion ability of $\mathrm{Cu}-\mathrm{W}$ becomes larger, the thickness of the gradient layer of $\mathrm{Cu}-\mathrm{W}$ is enlarged, and the inter-diffusion of $\mathrm{Cu}$ and $\mathrm{W}$ forms a metallurgical bond, thereby achieving the purpose of alleviating internal stress and forming a good combination of $\mathrm{Cu}-\mathrm{W}$ functionally graded materials. 


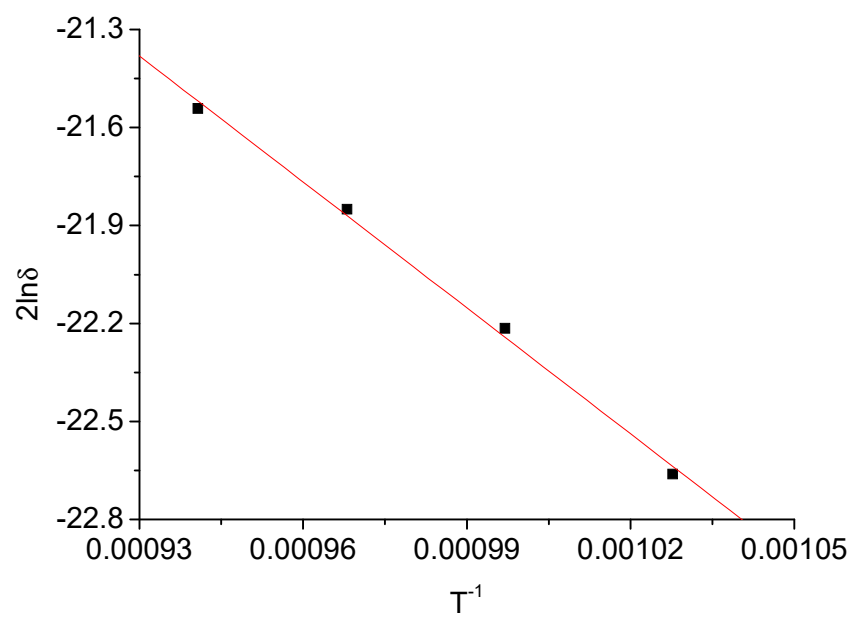

Figure 10. Relationship between $2 \ln \delta$ and $T^{-1}$.

\section{Conclusions}

(1) The condition for obtaining a dense and smooth $\mathrm{Cu}-\mathrm{Ni}$ gradient layer in a molten salt system with a molar ratio of $\mathrm{NaCl}: \mathrm{KCl}: \mathrm{NaF}: \mathrm{NiO}=0.36: 0.36: 0.25: 0.02$ is as follows: twoway pulse power supply (pulse cycle: $T=1000 \mathrm{~ms}$, the forward and reverse current ratio: $i_{\mathrm{f}} / i_{\mathrm{r}}=6: 1$; the forward and reverse time ratio: $\left.t_{\mathrm{f}} / t_{\mathrm{r}}=3: 1\right)$, current density of $70 \mathrm{~mA} \cdot \mathrm{cm}^{-2}$, electrodeposition temperature of $700{ }^{\circ} \mathrm{C}$, and electrodeposition time of $30 \mathrm{~min}$.

(2) When the molar ratio of the molten salt composition is $\mathrm{NaCl}: \mathrm{KCl}: \mathrm{NaF}: \mathrm{WO}_{3}=$ 0.3385:0.3385:0.25:0.073, the condition for obtaining a dense and smooth $\mathrm{Cu}-\mathrm{Ni}-\mathrm{W}$ gradient layer was as follows: the current density was $50 \mathrm{~mA} \cdot \mathrm{cm}^{-2}$, the electrodeposition temperature was $700^{\circ} \mathrm{C}$, bidirectional pulse electrodeposition was used, and the electrodeposition time was $20 \mathrm{~min}$.

(3) The addition of Ni element promotes the inter-diffusion between $\mathrm{Cu}$ and $\mathrm{W}$. The inter-diffusion coefficient at $700{ }^{\circ} \mathrm{C}$ is calculated to be $D=2.45 \times 10^{-13} \mathrm{~m}^{2} \cdot \mathrm{s}^{-1}$. The addition of Ni greatly increased the mutual diffusion coefficient $D$ of $\mathrm{Cu}-\mathrm{W}$. The thickness of the gradient layer of $\mathrm{Cu}-\mathrm{W}$ can reach $21 \mu \mathrm{m}$. Cu and $\mathrm{W}$ form a metallurgical bond, thereby achieving the purpose of alleviating internal stress and forming a well-bonded $\mathrm{Cu}-\mathrm{W}$ functionally graded material.

Author Contributions: Conceptualization, H.L.; data curation, J.L.; writing-original draft preparation, H.Y.; writing — review and editing, Y.L.; visualization, L.W. All authors have read and agreed to the published version of the manuscript.

Funding: This research was funded by the National Natural Science Foundation of China, grant number 51774143.

Data Availability Statement: Not applicable.

Acknowledgments: This work was supported by the National Natural Science Foundation of China (No. 51774143).

Conflicts of Interest: The authors declare no conflict of interest.

\section{References}

1. Ge, C.C.; Zhou, Z.; Ling, Y.H. New progress of metal-based functionally graded plasma-facing materials in China. Mater. Sci. Forum 2003, 423, 11-16. [CrossRef]

2. Han, J.C.; Xu, L.; Wang, B.L.; Zhang, X.H. Progress and prospects of functional gradient materials. J. Solid Rocket Technol. 2004, 27, 207-215.

3. Ling, Y.; Bai, X.; Zhou, Z.; Li, J.; Ge, C. Thermal shock behavior of W/Cu functionally gradient material. Rare Met. Mater. Eng. 2004, 33, 819-822.

4. You, J.H.; Bolt, H. Analytical method for thermal stress analysis of plasma facing materials. J. Nucl. Mater. 2001, 299, 9-19. [CrossRef] 
5. Chapa, J.; Reimanis, I. Modeling of thermal stresses of a graded Cu/W joint. J. Nucl. Mater. 2002, 303, 131-136. [CrossRef]

6. Senderoff, S.; Mellors, G. Coherent coatings of refractory metal. Science 1966, 153, 1475-1481. [CrossRef] [PubMed]

7. Masuda, M.; Takenishi, H.; Katagiri, A. Electrodeposition of tungsten and related voltammetric study in a basic $\mathrm{ZnCl}_{2}-\mathrm{NaCl}$ (40-60 mol \%) melt. J. Electrochem. Soc. 2001, 148, C59. [CrossRef]

8. Pavlovskii, V.A. Tungsten galvanic coatings deposited from salt melts. Prot. Met. 2006, 42, 170-173. [CrossRef]

9. Pavlovskii, V.A. Density and electrical conductivity of NaF-NaCl-WO 3 melts. Inorg. Mater. 2003, 39, 1208-1211. [CrossRef]

10. Koyama, K.; Morishita, M.; Umezu, T. Design of molten salt bath on the basis of acid-base cooperative reaction mechanism. Smooth electrodeposition of tungsten from $\mathrm{KF}^{-} \mathrm{B}_{2} \mathrm{O}_{3}-\mathrm{WO}_{3}$ molten salt. Electrochemistry 1999, 67, 677-683. [CrossRef]

11. Nitta, K.; Nohira, T.; Hagiwara, R.; Majima, M.; Inazawa, S. Characteristics of a tungsten film electrodeposited in a $\mathrm{KF}^{-\mathrm{B}_{2} \mathrm{O}_{3}-\mathrm{WO}_{3}}$ melt and preparation of $\mathrm{W}-\mathrm{Cu}-\mathrm{W}$ three-layered films for heat sink application. J. Appl. Electrochem. 2010, 40, 1443-1448. [CrossRef]

12. Boire-Lavigne, S.; Moreau, C.; Saint-Jacques, R. Relationship between the microstructure and thermal diffusivity of plasmasprayed tungsten coatings. J. Therm. Spray Technol. 1995, 4, 261-267. [CrossRef]

13. Dhote, A.; Ogale, S. Deposition of tungsten films by pulsed excimer laser ablation technique. Appl. Phys. Lett. 1994, 64, $2809-2811$. [CrossRef]

14. Varacalle, D.J., Jr.; Lundberg, L.; Jacox, M.; Hartenstine, J.; Ii, W.; Herman, H.; Bancke, G. Fabrication of tungsten coatings and monoliths using the vacuum plasma spray process. Surf. Coat. Technol. 1993, 61, 79-85.

15. Philipps, V. Tungsten as material for plasma-facing components in fusion devices. J. Nucl. Mater. 2011, 415, 2-9. [CrossRef]

16. Maier, H.; Kötterl, S.; Krieger, K.; Neu, R.; Balden, M. Performance of tungsten coatings as plasma facing components used in ASDEX Upgrade. J. Nucl. Mater. 1998, 258, 921-926. [CrossRef]

17. Fan, J.L.; Yan, D.J.; Huang, B.Y. The current research status of W-Cu composite material at home and abroad. Powder Metal. Ind. 2003, 13, 9-14.

18. Riccardi, B.; Montanari, R.; Casadei, M.; Costanza, G.; Chioni, G. Optimisation and characterisation of tungsten thick coatings on copper based alloy substrates. J. Nucl. Mater. 2006, 352, 29-35. [CrossRef]

19. Liu, X.; Yang, L.; Tamura, S.; Tokunaga, K.; Yoshida, N.; Noda, N.; Xu, Z. Thermal response of plasma sprayed tungsten coating to high heat flux. Fusion Eng. Des. 2004, 70, 341-349. [CrossRef]

20. Liu, Q.; Zhang, Y.; Liu, Y.; Xu, L.; Jiang, F. Research development of electrodeposited tungsten and tungsten alloys coating. Int. Mater. Rev. 2012, 26, 142-146.

21. Wang, X.Y.; Yang, H.L.; Feng, C.; Wang, Y.L.; Li, Y.G. Relationship between primary crystallization temperature of NaCl-KCl-NaF molten salt system and composition. Nonferr. Met. 2015, 5, 62-65.

22. Zhao, P.; Xie, F.Z.; Sun, W.S. Materials Science; Harbin Institute of Technology Press: Harbin, China, $1999 ;$ pp. $163-164$.

23. Cui, M.; Zhao, P. The Effect of cold plastic deformation on nitrogen in the deffusion activation energy of 38CrMoAlA steel. J. Met. Heat Treat. 1994, 15, 48-54. 